\title{
PEMANFAATAN KOMPOS UNTUK MENINGKATKAN HASIL STROBERI ORGANIK DI KOTA TOMOHON
}

\author{
COMPOST UTILIZATION TO INCREASE STRAWBERRY YIELD IN TOMOHON
}

Joice M.J. Supit, Yani E.B. Kamagi dan Wiesje Kumolontang*)

*Staf Dosen Agroekoteknologi Fakultas Pertanian Unsrat Manado, 95115

\begin{abstract}
Study on compost utilization to support organic strawberry production in Tomohon has been performed to promote the use of compost (mixture of chicken manure and rice husk) in organic strawberry and to determine the compost dosage producing highest strawberry yield. Completely randomized design (CRD) with 4 (four) replicates has been performed to apply various compost levels, namely 60 tha (SPo), 60 tha (SP1), 120 tha (SP2), 180 tha (SP3), and 240 tha (SP4). Data analysis has been conducted by means of analysis of variance (ANOVA) followed by the Least Significant Difference Test. The results revealed the significant yield differences among treatments. The highest result (28 fruits/ pot having 174.64 gram weight) was found in SP3 compost level (180 tha).

Key words: compost, agricultural land Rurukan Tomohon, strawberries
\end{abstract}

\begin{abstract}
ABSTRAK
Pemanfaatan kompos pada usahatani stroberi organik di Kota Tomohon bertujuan untuk menggalakkan penggunaan kompos (campuran kotoran ayam, sekam padi dan dedak) dalam usaha tani stroberi organic dan menentukan dosis yang menghasilkan stroberi tertinggi. Menggunakan rancangan acak lengkap (RAL), perlakuan kompos dosis 0 ton/ha (SPo), 60 ton/ha (SP1); 120 ton/ha (SP2); 180 ton/ha (SP3) dan 240 ton/ha (SP4) sebanyak 4 (empat) ulangan diberikan pada tanaman stroberi varietas jepang super. Analisis data dilakukan menggunakan analisis sidik ragam (Anova) yang dilanjutkan dengan uji beda nyata terkecil (BNT). Hasil penelitian menunjukkan adanya perbedaan nyata pada produksi stroberi dengan perlakuan berbagai dosis kompos. Hasil tertinggi (28 buah/pot seberat 174,64 gram) diberikan oleh perlakuan SP3 (180 ton/ha).

Kata kunci: kompos, stroberi, lahan pertanian Rurukan Tomohon
\end{abstract}

Eugenia Volume 22 No. 3 Oktober 2016 


\section{PENDAHULUAN}

Kemajuan Iptek yang dihasilkan sejak tahun 1970an di bidang pertanian telah dirasakan dalam peningkatan produksi baik tanaman semusim maupun tanaman tahunan. Adapun teknologi pertanian tersebut adalah pupuk dan pestisida serta teknik konservasi tanah yang bertujuan untuk meningkatkan dan serta mempertahankan produksi pertanian. Tetapi dengan adanya pengkajian yang lebih mendalam terhadap teknologi pertanian khususnya pupuk dan pestisida telah menunjukkan teknologi tersebut tidak ramah lingkungan.

Dalam rangka menghasilkan produksi pertanian organik maka harus menggunakan teknologi pertanian yang ramah lingkungan seperti pupuk organik dengan menggunakan kompos atau pupuk kandang, sedangkan untuk pertisida dapat menggunakan pestisida yang bahan bakunya berasal dari tanaman. Kompos adalah bahan organik yang berasal dari sisa-sisa tanaman yang telah menjadi lapuk, seperti daun-daunan, jerami, alang-alang, rumput-rumputan, serta kotoran hewan. Peran bahan organik yang telah menjadi kompos terhadap sifat fisik tanah di antaranya merangsang granulasi, memperbaiki aerasi tanah, dan meningkatkan kemampuan menahan air. Untuk melihat sejauhmana peran kompos sebagai pupuk akan menghasilkan produksi pertanian organik, maka dilakukan kajian pemanfaatan kompos pada tanaman stroberi di Kota Tomohon. Produksi pertanian organik adalah produksi pertanian yang menggunakan pupuk dan pestisida yang ramah lingkungan. Pada saat ini permintaan produk pertanian organik cukup meningkat seiring dengan kesadaran akan kesehatan dari konsumen. Namun, ketersediaan produk pertanian yang organik belum tersedia banyak juga terkendala dengan harga yang tinggi dibandingkan dengan produk pertanian anorganik.

Stroberi merupakan tanaman buah berupa herba yang termasuk keluarga : Rosaceae; genus : Fragaria dan spesies : Fragaria spp. Tanaman ini memiliki kurang lebih 20 spesies. Buah stroberi berwarna hijau keputihan ketika sedang berkembang, dan pada kebanyakan spesies berubah menjadi merah ketika masak. Tanaman Stoberi tumbuh pada ketinggian ideal antara 1000-2000 mdpl, dengan lama penyinaran matahari 8-10 jam per hari, curah hujan berkisar $600-700 \mathrm{~mm}$ per tahun. Suhu udara optimum antara $17-20^{\circ} \mathrm{C}$ dan suhu udara minimum antara $4-5^{\circ} \mathrm{C}$ dengan kelembaban udara $80-90 \%$. Tanah merupakan salah satu sumberdaya alam yang memiliki peranan penting dalam ekosistem, diantaranya sebagai tempat tumbuh tanaman, habitat bagi jasad tanah, media bagi kontruksi, sistem daur ulang bagi unsur hara dan sisa-sisa organik serta sistem pasokan dan penyaringan air (Rayes, 2007).

Kompos adalah bahan organik yang telah menjadi lapuk, seperti daun daunan, jerami, alangalang, rumput-rumputan, dedak padi, batang jagung, sulur, carang-carang serta kotoran hewan. Bila bahan-bahan itu sudah hancur dan lapuk, disebut pupuk organis. Jenis-jenis bahan ini akan menjadi lapuk dan busuk bila berada dalam keadaan basah dan lembab dan akan berubah menjadi bagian dari tanah. Hakim dkk. (1986) mengemukakan sebagai pupuk yang berasal dari sisa-sisa organik berupa tanaman, kotoran padat dan cair hewan ternak, serta kotoran burung laut dan kelelawar yang telah mengalami proses pelapukan. Pada umumnya pupuk organik mengandung unsur hara lebih lengkap yaitu unsur hara makro dan mikro meskipun dalam jumlah yang sedikit. Pemberian pupuk organik ke dalam tanah membawa dampak positif bagi tanah dan tanaman. Peranan bahan organik di dalam tanah adalah memperbaiki sifat fisik, kimia dan biologi tanah.

Menurut Utomo (2007), adanya penambahan unsur hara, humus, dan bahan organik ke dalam tanah menimbulkan efek residual, yaitu berpengaruh dalam jangka panjang. Bahan organik dihasilkan oleh tumbuhan melalui proses fotosintesis, sehingga unsur karbon (C) merupakan penyusun utama dari bahan organik tersebut yang berada dalam bentuk senyawa-senyawa polisakarida, seperti: selulosa, hemiselulosa, pati, serta bahan-bahan pektin dan lignim.

Kota Tomohon yang terletak di dataran tinggi merupakan wilayah agraris, di mana sebagian besar sumber penghidupan penduduknya berasal dari kegiatan pertanian tanaman semusim dan bunga-bungaan. Lahan yang ada di wilayah ini dalam usaha pertaniannya oleh petani lebih umum 
menggunakan pupuk anorganik. Kondisi ini jelas menghasilkan produk pertanian yang anorganik. Usahatani stroberi organic di sentra produksi hortikultura Rurukan Tomohon mulai berkembang dalam lima tahun terakhir.

Penelitian terkait pemanfaatan kompos untuk meningkatkan produksi stroberi pernah dilakukan oleh Hammad, et. al., 2014, Shehata, et. al., 2011, dan Hargreaves, et. al., 2009. Untuk mengoptimalkan produksi pertanian organik maka masukan teknologi penggunaan pupuk organik/ kompos menjadi perhatian untuk petani stroberi di Kelurahan Rurukan. Penelitian ini bertujuan untuk a) meningkatkan penggunaan pupuk kompos dalam usaha tanaman stroberi organik yang ramah lingkungan; b) menentukan dosis pupuk kompos yang optimal untuk usaha tanaman stroberi; dan c) memperbaiki sifat fisik dan kimia tanah bagi lahan agar menjadi produktif dalam usaha pertanian. Meningkatnya penggunaan kompos khususnya pada usahatani stroberi diharapkan dapat membuka lapangan kerja dan akan meningkatkan kesejahteraan bagi masyarakat yang ada di pedesaan.

\section{METODE PENELITIAN}

Penelitian dilaksanakan di Kelurahan Rurukan Kota Tomohon dengan waktu penelitian mulai bulan Mei - September 2015. Kegiatan analisis kandungan unsur hara tanah dilakukan di Laboratorium Jurusan Tanah Fakultas Pertanian Unsrat. Bahan yang digunakan adalah: bibit stroberi (varietas Jepang super) dan kompos. Alat yang digunakan adalah: ember, meteran, timbangan, karung, ayakan, parang, sekop, polibag dan alat tulis-menulis. Variabel yang diamati adalah : 1). Ketersediaan unsur hara di kompos dan di tanah, yaitu : C organik, N, P, K dan pH pada kondisi sebelum dan sesudah perlakuan. 2). Jumlah dan berat buah stroberi. Metode penelitian yang dilakukan adalah : rancangan dasar acak lengkap (RAL) dengan 4 ulangan. Perlakuan pupuk kompos : 0 ton/ha (0 gr/pot) sebagai kontrol (SPo), 60 ton/ha (150gr/pot) (SP1), 120 ton/ha (300 gr/pot) (SP2), 180 ton/ha (450 gr/pot) (SP3), dan 240 ton/ha (600 $\mathrm{gr} /$ pot) (SP4). Prosedur penelitian meliputi tahapan: 1). Tanah bekas yang diberi pupuk organik dimasukan kedalam ember kemudiaan disirami/inkubasi selama dua minggu; 2). Setelah seminggu bibit tanaman di tanam di pot; 3). Setelah 10 hari dilakukan penjarangan dimana setiap ember dibiarkan 2 tanaman; 4). Pemeliharaan tanaman sampai umur produktif. Data hasil penelitian ditabulasi dan dianalisis dengan Analisis Sidik Ragam (Anova) dan apabila berpengaruh dilanjutkan uji beda nyata terkecil (BNT) $5 \%$.

\section{HASIL DAN PEMBAHASAN}

Lokasi penelitian terletak di Kelurahan Rurukan Kota Tomohon pada ketinggian sekitar 1170 mdpl. Mempunyai jenis tanah Andisol dengan tekstur tanah lempung berdebu (pasir: 28,59\%; debu: $54,48 \%$; liat: $16,96 \%$ ). Hasil analisis tanah awal dan akhir penelitian seperti pada Tabel 1.

Hasil analisis sifat kimia tanah sebelum perlakuan (Tabel 1) menunjukkan bahwa tanah lokasi penelitian kandungan haranya tergolong rendah. Ini menunjukkan bahwa tanah lokasi penelitian akan memberikan produksi yang rendah, apabila ditanami tanaman tanpa adanya usaha pemupukan. Pemberian pupuk bertujuan untuk menambah hara yang dibutuhkan oleh tanaman.

Dari hasil analisis tanah sesudah diberikan perlakuan pupuk kompos (Tabel 1), menunjukkan bahwa adanya peningkatan hara pada tanah antara perlakuan SP0 dengan perlakuan SP1, SP2, SP3 dan SP4. Kondisi ini menunjukkan bahwa pemberian pupuk organis / kompos diperlukan lebih banyak jumlah atau dosisnya dibandingkan dengan pupuk anorganik dalam hal ketersediaan haranya.

Kompos yang digunakan dalam penelitian merupakan campuran antara pupuk kandang (kotoran ayam), sekam padi dan dedak dimana hasil analisis kimia kompos seperti pada Tabel 2. 
Tabel 1. Hasil Analisis Beberapa Sifat Kimia Tanah Awal dan Akhir Penelitian

(Table 1. Soil Chemical Properties Before and After Experiment)

\begin{tabular}{|c|c|c|c|c|c|c|c|}
\hline \multirow{3}{*}{ Jenis Analisis } & \multicolumn{6}{|c|}{ Hasil Analisis Tanah } & \multirow{3}{*}{ Keterangan } \\
\hline & \multirow{2}{*}{$\begin{array}{c}\text { Awal } \\
\text { (Rata-rata) }\end{array}$} & \multicolumn{5}{|c|}{ Akhir / Perlakuan } & \\
\hline & & SPo & SP1 & SP2 & SP3 & SP4 & \\
\hline $\mathrm{pH} \mathrm{H} \mathrm{H}_{2} \mathrm{O}$ & 5,84 & 6,59 & 6,63 & 6,66 & 6,66 & 6,67 & $\begin{array}{l}\text { Agak masam- } \\
\text { netral }\end{array}$ \\
\hline C org $(\%)$ & 2,83 & 1,53 & 1,83 & 4,27 & 5,29 & 5,49 & $\begin{array}{l}\text { Rendah-sangat } \\
\text { tinggi }\end{array}$ \\
\hline $\mathrm{N}$ total $(\%)$ & 0,17 & 0,14 & 0,16 & 0,19 & 0,42 & 0,51 & Rendah-tinggi \\
\hline P tersedia (ppm) & 16,87 & 15,36 & 16,22 & 16,35 & 19,24 & 23,16 & Rendah-sedang \\
\hline K tersedia (ppm) & 6,0 & 2,67 & 3,44 & 5,18 & 5,76 & 8,66 & Sangat Rendah \\
\hline
\end{tabular}

Tabel 2. Komposisi Kimia Kompos

(Table 2. Chemical Composition of Compost)

\begin{tabular}{lcc}
\hline & Komposisi & Hasil \\
\hline $\mathrm{N}(\%)$ & 1,11 \\
$\mathrm{P}$ tersedia $(\mathrm{ppm})$ & 22,34 \\
$\mathrm{~K}$ tersedia $(\mathrm{ppm})$ & 20,23 \\
$\mathrm{C}$ organik $(\%)$ & 15,11 \\
$\mathrm{pH}$ & 6,37 \\
\hline
\end{tabular}

Berdasarkan hasil analisis pada Tabel 2, dapat dilihat kandungan hara pada kompos di mana untuk $\mathrm{N}$ tergolong sangat tinggi, $\mathrm{P}$ dan tergolong sedang, $\mathrm{P}$ dan $\mathrm{K}, \mathrm{C}$ organik tergolong sangat tinggi dan $\mathrm{pH}$ kompos tergolong agak masam. Dengan melihat kandungan hara pada tanah di lokasi penelitian yang rendah, maka apabila dilakukan pemupukan dengan kompos, maka kompos akan memberikan konstribusi hara pada tanaman dalam memenuhi kebutuhan hara dari tanaman selama masa pertumbuhannya.

\section{Jumlah Buah Stroberi}

Hasil pengamatan pengaruh pemberian kompos terhadap jumlah buah stroberi dapat dilihat pada Tabel 3.

Tabel 3, menunjukkan adanya perbedaan yang nyata antar perlakuan terhadap jumlah buah stroberi. Perlakuan tanpa pemberian kompos (SPo) menunjukan hasil paling rendah sedangkan tertinggi berada pada perlakuan SP3 dengan dosis 180 ton/ha. Hal ini menunjukkan bahwa pemberian dosis pada perlakuan SP3 sudah dapat memenuhi kebutuhan hara yang dibutuhkan tanaman dalam proses pertumbuhan dan produksinya.

Gambar 1 dengan jelas memperlihatkan bagaimana peningkatan jumlah buah stroberi dengan meningkatnya pemberian kompos dan tertinggi pada perlakuan SP3 dan kembali menurun dengan bertambahnya pemberian kompos. Pemberian kompos yang terlalu banyak tidak lagi memberikan hasil yang maksimal karena kemungkinan pertumbuhan vegetatif yang baik tetapi pertumbuhan generatif tidak meningkat lagi. Hal ini kemungkinan dengan meningkatnya jumlah kompos yang diberikan kandungan nitrogen meningkat tetapi tidak digunakan lagi oleh tanaman. Selain itu kompos akan memberikan efek residu atau hasil yang baik pada penanaman berikutnya.

Hakim, dkk. (1986) mengemukakan bahwa bahan organik dapat mempengaruhi sifat kimia tanah berupa pengikatan unsur $N, P$, dan $S$ dalam bentuk organik atau dalam tubuh mikroorganisme, sehingga terhindar dari pencucian, yang kemudian unsur-unsur tersebut dapat tersedia kembali. Penambahan bahan organik ke dalam tanah dapat 
meningkatkan ketersediaan $\mathrm{P}$ di dalam tanah. Sutanto (2002), penggunaan pupuk organik yang tepat waktu dan cukup akan meningkatkan hasil tanaman. Pupuk organik berperan pada sifat fisik tanah, kimia dan biologi tanah (Stevenson,1994). Peranan pupuk organik terhadap sifat fisik tanah adalah memperbaiki struktur tanah. Pada perbaikan sifat kimia tanah pupuk organik menyumbang hara ke tanah dan meningkatkan kapasitas tukar kation (KTK) tanah. Sedangkan perbaikan sifat biologi tanah, pupuk organik yang berasal dari berbagai sumber bahan organik dapat membawa jasad renik yang bermanfaat bagi perbaikan sifat fisik dan kimia tanah, pada akhirnya akan berpengaruh positif pada pertumbuhan dan hasil tanaman.

\section{Berat Buah Stroberi}

Hasil pengamatan pengaruh pemberian kompos terhadap berat buah stroberi dapat dilihat pada Tabel 4.

Tabel 4, menunjukkan bahwa adanya perbedaan yang nyata antar perlakuan terhadap berat buah stroberi. Pada perlakuan SPo, menunjukan hasil paling rendah sedangkan tertinggi berada pada perlakuan SP3 dengan dosis 180 ton/ha. Hal ini menunjukkan bahwa pemberian dengan dosis pada SP3 sudah dapat memenuhi kebutuhan hara yang dibutuhkan tanaman dalam proses pertumbuhan dan produksi tanaman.

Gambar 2, memperlihatkan dengan jelas peningkatan produksi buah stroberi dengan me- ningkatnya pemberian kompos, dan menurun pada pemberian SP4, seperti halnya dengan jumlah buah. Hal ini menunjukkan dengan peningkatan jumlah buah maka berat buah juga meningkat. Pemberian kompos dapat menyumbangkan sejumlah unsur hara yang dibutuhkan tanaman dalam proses pertumbuhan dan produksi. Unsur hara makro yang dibutuhkan tanaman dalam hal ini nitrogen, fosfor dan kalium umumnya tersedia pada kompos dan dapat digunakan tanaman.

Dari gambar 2 menunjukkan bahwa perlakuan SP3 memberikan produksi tertinggi buah stroberi dengan persamaan nilai duga yaitu : $y=$ $60,42 x^{0,697}$. Selanjutnya dari Gambar 2, terlihat bahwa peningkatan dosis seperti pada perlakuan SP4 tidak memberikan tambahan hasil buah stroberi. Menurut Djoehana (1986), penggunaan pupuk organik dimaksudkan untuk menambah kandungan bahan organik tanah dan memperbaiki sifat fisik tanah terutama struktur dan porositas tanah agar jumlah hara yang dibutuhkan oleh tanaman lebih banyak tersedia.

Kendala dari penelitian adalah air tidak tersedia cukup di lokasi penelitian untuk penyiraman tanaman. Keadaan ini menyebabkan kelembaban tanah tidak dapat dipertahankan selama penelitian. Kondisi ini sangat berpengaruh pada produksi tanaman stroberi. Menurut Kohnke (1968) bahwa air diperlukan tanaman karena air mempengaruhi banyak reaksi fisika dan kimia tanah.

Tabel 3. Rata-Rata Jumlah Buah Stroberi

(Table 3. Average Number of Strawberries)

\begin{tabular}{cc}
\hline Perlakuan & Rata-rata \\
\hline SPo & $11,00 \mathrm{a}$ \\
SP1 & $15,75 \mathrm{~b}$ \\
SP2 & $20,00 \mathrm{c}$ \\
SP3 & $28,00 \mathrm{e}$ \\
SP4 & $21,50 \mathrm{~d}$ \\
BNT 5 \% & 1,38 \\
\hline
\end{tabular}




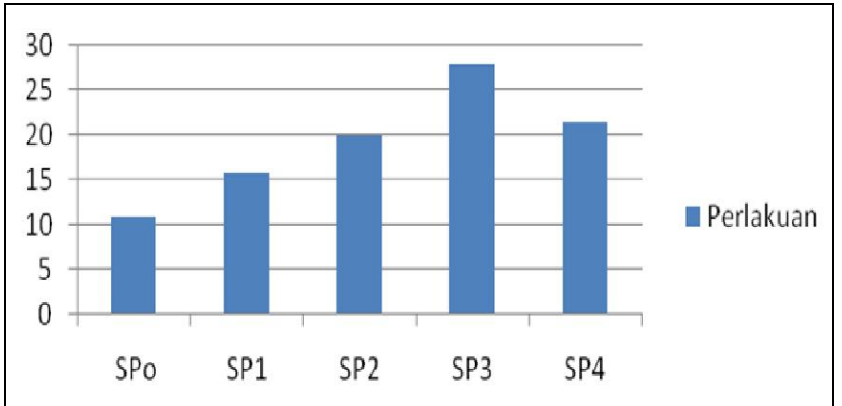

Gambar 1. Tampilan Jumlah Buah Pada Tiap Perlakuan

(Figure 1. Number of Fruits for Each Treatment)

Tabel 4. Rata-Rata Berat Buah Stroberi

(Table 4. Average Weight of Srawberries)

\begin{tabular}{cc}
\hline Perlakuan & Rata-rata (gr) \\
\hline SPo & $55,89 \mathrm{a}$ \\
SP1 & $103,86 \mathrm{~b}$ \\
SP2 & $143,62 \mathrm{c}$ \\
SP3 & $174,64 \mathrm{e}$ \\
SP4 & $155,85 \mathrm{~d}$ \\
BNT 5\% & 4,852 \\
\hline
\end{tabular}

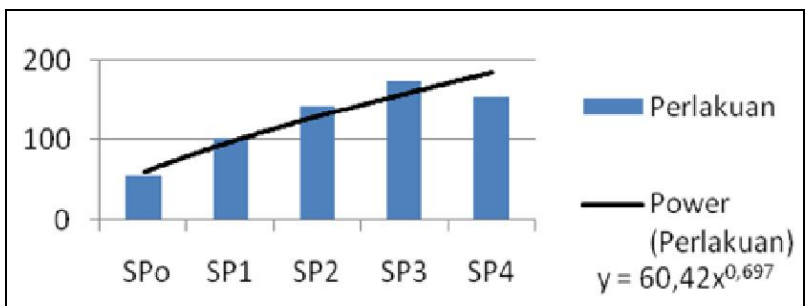

Gambar 2. Tampilan Buah Stroberi Tiap Perlakuan

(Figure 2. The Number of Strawberry Fruit for Each Treatment)

\section{KESIMPULAN DAN SARAN}

\section{Kesimpulan}

Berdasarkan hasil uji statistik terdapat perbedaan yang nyata antara perlakukan SPo, SP1, SP2, SP3 dan SP4.

Hasil tertinggi terdapat pada perlakuan SP3 dengan dosis 180 ton/ha dengan jumlah buah sebanyak 28,00 buah per pot dan berat buah sebesar 174,64 gram. $60,42 x^{0,697}$.
Saran

Perlu menjaga kelembaban tanah selama masa pertumbuhan tanaman.

Perlu dilanjutkan dengan percobaan lapangan pengaruh perlakuan pupuk kompos terhadap produksi tanaman stroberi.

\section{DAFTAR PUSTAKA}

Djoehana, S. 1986. Pupuk dan Pemupukan. CV.Yasaguna. Jakarta. 
Hakim, N.M.Y., Nyakpa, A.A.. Lubis, S.G. Nugroho, M. R. Saul, M.A. Diha, Go Ban Hong dan H.H. Baileng. 1986. Dasar-Dasar IImu Tanah. Universitas Lampung.

Hammad, S., T. Elzehery, dan A. Ramadan, 2014. Influence of Compost, Effective Microorganism, and Potassium on Strawberry Production in Sandy Soils. ISHS Acta Horticulturae 1049: VII International Strawberry Symposium.

Hargreaves, J.C., M.S. Adl and P.R. Warman, 2009. The Effects of Municipal Solid Waste Compost and Compost Tea on Mineral Element Uptake and Fruit Quality of Strawberries. Compost Science \& Utilization, (2009), Vol. 17, No. 2, 85-94.

Khonke, H. 1968. Soil Physics. Tata McGraw Hill. Bombay.
Rayes, M. dan R.M. Luthfi. 2007. Metode Inventarisasi Sumber Daya Lahan. Penerbit Andi. Yogyakarta.

Shehata, S. A, Gharib, A. A, Mohamed M. El-Mogy, Abdel Gawad, K. F. and Emad A. Shalaby, 2011. Influence of compost, amino and humic acids on the growth, yield and chemical parameters of strawberries. Journal of Medicinal Plants Research Vol. 5(11), pp. 2304-2308.

Stevenson. 1994. Humus Chemistry: Genesis, Composition, Reaction, $2^{\text {nd }}$ edt. John Wiley and Sons. Canada.

Sutanto, R. 2002. Penerapan Pertanian Organik. Pemasyarakatan dan Pengembangannya. Penerbit Kanisius. Yogyakarta.

Utomo, A. 2007. Pembuatan Kompos dengan Limbah Organik. CV Sinar Cemerlang Abadi. 